\title{
Oral cancer: from bench to bedside, the continuous effort towards better diagnostic, treatment and prognostic tools
}

\author{
Gustavo Pompermaier GARLET \\ Co-Editor-in-Chief \\ Journal of Applied Oral Science
}

\section{Dear Readers,}

Oral cancer comprises a major clinical challenge in Oral Sciences fields, and in this issue of the Journal of Applied Oral Science, we are glad to present examples of bench to bedside continuous effort towards better diagnostic, treatment and prognostic tools to improve the clinical management of oral cancer.

Starting at the bedside end, MENEZES, et al. ${ }^{1}$ (2013) describe a rare case of mandibular bone metastasis derived from a tumoral prostate adenocarcinoma. While oral cavity and associated tissues are uncommon locations for metastatic tumor spread, bone metastasis is even rarer. In the reported case, the authors describe all the sequence of clinical and radiographic examination, medical history investigation, bone scintilography, incisional biopsy and immunohistochemical analysis of mandibular lesions that allowed the definitive diagnosis, and the subsequent treatment and clinical outcome monitoring.

While the prostate adenocarcinoma-derived mandibular bone metastasis comprises an infrequent finding that substantiates a case report, oral squamous cell carcinoma (OSCC) remains as the most common oral neoplasm. Considering that important variations are described in some demographic and clinicopathological aspects of OSCC, a long term (8 years) analysis of more than 300 cases was performed in a Brazilian population, classically described as highly miscegenated from the genetic viewpoint, which contrasts with the more homogenous genetic profiles of the North Americans, Europeans and Asians cohorts used to generate the majority of epidemiological data related to OSCC. In this notable clinical and histopathological effort, PIRES, et al. $^{3}$ (2013), characterized the OSCC occurrences at the Oral Pathology service of the School of Dentistry, State University of Rio de Janeiro, a reference center for Oral Pathology in Rio de Janeiro metropolitan area. Within a series of conclusions, the authors describe the early and more frequent prevalence of OSCC in males, and that the areas affected by OSCC, as well the degree of tumors differentiation, differ in males and females.
Finally, completing the bench-bedside aspect, PEREIRA, et al. ${ }^{2}$ (2013) investigated the expression profiles of $\mathrm{MSH} 2$, a DNA repair protein, in head and neck squamous cell carcinoma (HNSCC). It is important to mention that OSCC is a subgroup of HNSCC. By means of clinical, histopathological and immunohistochemical analysis, the authors describe that $\mathrm{MSH} 2$ expression in HNSCC tissues was associated with increased overall survival of patients. In mechanistic terms, $\mathrm{MSH} 2$ comprises a widely expressed DNA repair protein, being its inactivation associated with pathologic consequences on DNA. Despite the possible molecular mechanisms underlying the control of $\mathrm{MSH} 2$ expression in HNSCC (from mutations to epigenetic modulation), a reduced expression of $\mathrm{MSH} 2$ was associated with a poor odds ratio (2.943) of HNSCC prognosis.

Therefore, the three studies mentioned are interesting examples of the current effort to understand and manage oral cavity related cancer, where clinical and laboratorial researchers interplay, despite the parallel or collaborative nature, in order to provide new information to support the development of better diagnostic and treatment tools and strategies to manage oral tumors.

\section{REFERENCES}

1- Menezes JDS, Capellari PFM, Capelari MM, Gonçalves PZ, Toledo GL, Toledo JL Filho, et al. Mandibular metastasis of adenocarcinoma from prostate cancer: case report according to epidemiology and current therapeutical trends of the advanced prostate cancer. J Appl Oral Sci. 2013;21(5):490-5

2- Pereira CS, Oliveira MVM, Barros LO, Bandeira G, Santos SHS, Basile JR, et al. Low wxpression of MSH2 DNA repair protein is associated with poor prognosis in head and neck squamous cell carcinoma. J Appl Oral Sci. 2013;21(5):426-21.

3- Pires FR, Ramos AB, Oliveira JBC, Tavares AS, Luz PSR, Santos RB. Oral squamous cell carcinoma: clinicopathological features from 346 cases from a single oral pathology service during an 8-year. J Appl Oral Sci. 2013;21(5):460-7. 